\title{
Unexpected Serious Risk
}

National Cancer Institute

\section{Source}

National Cancer Institute. Unexpected Serious Risk. NCI Thesaurus. Code C142745.

A serious adverse drug experience that is not listed in the labeling of a drug, or that may be symptomatically or pathophysiologically related to an adverse drug experience identified in the labeling, but differs because of greater severity, specificity, or prevalence. [505-1(b) of FD\&C Act (21 USC. 355-1(b) 